\title{
Journal of Medical Thesis: Creation of A Unique Paradigm - Principles and Vision
}

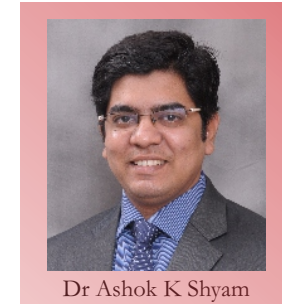

Dr Ashok K Shyam

MS Orthopaedics

Editor - Journal of Medical Thesis

Email: drashokshyam@yahoo.co.uk

\section{What is Research?}

The answer to this question can be variously defined and described but simply put Research is 'Pursuit of Knowledge'. In scientific academia there are three steps to build knowledge viz data acquisition, processing the data to generate information and analyzing the information to produce knowledge. All three components are important parts of the process of pursuit of Knowledge. Now as a part of medical curriculum every student has to undertake a thesis which involves all three stages of knowledge building. The problem here is that this data (due to some unforeseen reason) fails to show up in public domain. With public domain I also mean easily accessible portals and not dusty offices and store rooms. The definition of public domain has changed in recent years and for academia it means availability of the work on World Wide Web. The non availability of theses on the internet makes them 'Grey Literature' as pointed by Ms Punita Solanki in one of the guest Editorial in this issue [1]. This lack of accessibility leads to certain unique problems in Knowledge building process as listed below

Gaps in the Collage: Currently in the modern framework of Pursuit of Knowledge, the term Evidence based medicine (EBM) has come into importance. Although I personally may not totally agree with all the principles of EBM, but the point it makes is that it's important to create a 'Collage' of all available research in form of a systematic review or Metanalysis. The data for the Metanalysis comes from many different studies and the strength of Metanalysis is its numbers. More the number of patients more strong are the results. Metanalysis search is generally done on the internet through various databases like Pubmed, Ovid, google etc. Although some Metanalysis do review hard bound literature, yet most will restrict themselves to online available articles. Thus if thesis are not available online they cannot be included in the EBM search. Although some may argue that thesis are of low quality, but then it is a 'Research' document. Even if the data is small or not designed properly, the patients are assessed and data is there and according to the research question and design of Metanalysis, this data can be used in preparing the Evidence Collage. Also since Evidence is built on 'Available' data this may seriously bias the results of EBM statistics. Say for example I know that a lot of thesis have been done on proximal femur fractures. Almost every year around 20 to 30 students of orthopaedics do a thesis on proximal Femur fracture in India and they enroll around 50 patient on an average. If we take an average of last 10 years with 20 students every years the potential database includes ten thousand patients of Proximal femur fracture. Also if we start considering other countries, I am sure the numbers will be much more. The amount of data that we are missing here is humungous and if it was made available, it would have definitely changed the face of current knowledge about proximal femur fractures. Publication of these thesis in Journal of Medical thesis will help build a body of literature which will definitely add to Evidence by it sheer numbers. Journal of Medical Thesis is here to build this parallel body of Literature and in years to come we will definitely change the decision making scenario

Circling one's Tail: When we start a research project one of the first step is reviewing the literature to find the current status on the research question we want to pursue. Like the above example of proximal femur fractures, I have seen same topics repeated year after year. The problem is while reviewing the literature (which is done online) the thesis of the past year do not show up on search engines and hence the student chooses a topic thinking that it has not been done in the past, thus duplicating the research. New research is built upon past research like building a wall one brick by brick. Or rather like a jigsaw puzzle, where the entire scenario of a disease entity is a Jigsaw and by doing research we create small pieces that fit into a jigsaw. Duplication of research is like creating multiple copies of same piece of jigsaw every year and the reason for it is that every new student is unaware that this particular piece is already fabricated by a candidate in last year. This not only creates multiple copies of jigsaw more importantly it obstructs creation of new parts of the framework. So if a student is aware that this particular topic is done multiple times, he and his guide will not repeat it and instead pursue a fresh topic which can add to the process of generating new answers. Thus non publication of thesis not only lead us to multiplicity of theses but also prevents generation of new hypothesis 
and studies. It's like we keep on chasing our tails every year and remain on the same spot without progressing at the speed we are capable of.

Loss of Resources: As pointed above multiplicity of thesis after certain point will stop adding value to the evidence collage and will just be a waste of resources. The thesis requires a lot of time and dedication from everyone involved and if it is not going to add any value to the existing body of knowledge all this effort will be wasted. This waste of resources can be avoided by publishing the thesis in JMT and this can be achieved more effectively by increased collaboration amongst academic bodies and JMT. At JMT we encourage increased collaboration not only within one faculty or institute but between multiple faculties and many institutes thus effectively creating a strong academic network. With this in mind we will like to invite Individual departments, Medical colleges, Institutes, Universities and other academic bodies to associate with Journal of Medical thesis. All associated bodies will be duly acknowledged on our website and enlisted in the Journal. If you wish your department, institute or university to be affiliated with JMT, please write to us directly at journalmedicalthesis@gmail.com

Failure to build Value: This is one of the most important point. When I visited my medical college few years back, I made a point to go and look for our thesis. They were all there in the corner of the library and looked as if no one has ever touched them. The emotion it identified with was not remotely of 'value'. Generating personal value into things we do is a natural human trait. If we are investing time and effort into a project we wish to create value out of it. Seeing my thesis lying in a dusty cupboard did not give me any sense of value created. Again another aspect of medical research is patients' point of view. When we conduct out thesis and enroll patients, most patients agree to get enrolled as they think that their participation in research will create something of value and will help in progress of knowledge and might help the next patient to get better treatment. If we fail to add this data to the existing knowledge database, we also fail to create value for the patients who co-operated with us. This according to me also breaches Ethical borders and our promise to patients enrolled in the thesis. This I feel is one of the strong reason why all thesis should be published and brought into public domain. The third point of value lies with the student. Thesis is often the first research projects done by a medical student (at least in India) and with his limited knowledge and guidance from his guide he tries to make an effort in this new arena of medical research. Like any new entrepreneur he needs encouragement at every step. If his first step in medical research namely his thesis fails to create any value, I doubt he will ever try to take up another project. On the other hand if his thesis does get published and does create value (may be small or miniscule), it will definitely provide encouragement toward taking further steps in research. As said above Research is Pursuit of knowledge and having more researchers pursuing knowledge is not only better for the subject but also better for our patients. Creating value out of thesis is one of the core principles of JMT and I believe it will be the first step in creating Clinicians-Scientists which is a breed that needs to be nurtured for progress of our faculty.

So by above logic, thesis seem to be quite important and can add greatly to academic literature, so why have they been given stepmotherly treatment by the current framework of literature. Possibly, since this is the first attempt by the researcher, it is considered to be having poor design and other issues as pointed out by Dr VM Iyer in his guest editorial [2]. However I feel if we start putting value in these thesis by publishing them, the future students will also start putting in more efforts and making their thesis more relevant. This it's a like a positive feedback loop; we give thesis value by publishing and students by appreciating this value put more effort in making thesis better. This is positive feedback is one of the core principles on which Journal of Medical thesis is based on. We hope this will break the existing Negative feedback loop for thesis, prevent duplication of thesis, avoid plagiarism and also encourage students towards generating better thesis. Also as mentioned by our Associate Editor Dr Hrutvij Bhatt in his Guest Editorial [3] JMT will also envisioned to provide help to students in terms of organizing thesis workshops and online courses. Thus JMT will not only be a journal but will be a complete portal for Medial thesis, providing assistance to young researchers and helping create quality research. Thus JMT will be creating a Unique Paradigm with strong core principles and innovative visions for the future of medical thesis.

This is the inaugural issue of Journal of Medical thesis and includes thesis from various faculties of medicine, including orthopaedics, general medicine, general surgery, anesthesia and physiotherapy. We have a star studded Editorial board with more than 80 faculties from almost all areas of medicine. I would take this opportunity to thank the editorial board members for their co-operation and encouragements and we all look forward to achieving the goals we have set for JMT. The format of JMT looks beautiful with authors photographs and includes and abstract and thesis summary. The full thesis along will the data chart is also available online.

We are open to suggestions and if you wish please write a letter to Editor to us (details of submission on website www.journalmedicalthesis.com ). Do also visit us on facebook and twitter where we will be posting regular updates about the Journal. With first issue online we have send the documents for Indexing of JMT and soon will receive ISSN number and other indexing. We have just started this journey and I am sure there will be shortcomings in the beginning but I assure you that we are 
here to stay and with help from our editorial board, authors and readers we will definitely achieve what we have envisioned and possibly more. This is a collective small step towards a big leap together.

With this I leave you to enjoy the First Issue of Journal of Medical thesis.

\section{Bibliography}

1. Solanki PV.JMT GuestEditorial:Punita V. Solanki.Journal Medical Thesis 2013 July-Sep; 1(1):4-5

2. VM Iyer. JMT Guest Editorial: Dr V M Iyer. Journal Medical Thesis 2013 July-Sep; 1(1):6

3. H Bhatt. JMT GuestEditorial:Dr Hrutvij Bhatt. Journal Medical Thesis 2013 July-Sep; 1(1):7

Conflict of Interest: Nil

Source of Support: None

Full Text available on www.journalmedicalthesis.com

How to Cite this Article: Shyam AK. Editorial: Journal of Medical Thesis: Creation of A Unique Paradigm - Principles and Vision.

Journal Medical Thesis 2013 July-Sep; 1(1):1-3. 